\title{
Cardiac arrest centers - the future?
}

\author{
Christian Storm \\ From Targeted Temperature Management (TTM 2014) \\ Berlin, Germany. 6-7 November 2014
}

Target temperature management should be state of the art nowadays after cardiac arrest. With gaining knowledge about reperfusion injury after general hypoxia it became obvious that intensive care treatment contains a bundle of different steps rather than only cooling the patient. In trauma patients, outcome was improved by treatment in high-volume centers with high experience $[1,2]$. Concerning the overall outcome and length of stay, trauma patients benefit from admission to a trauma center. However, current data show a higher survival rate after cardiac arrest if hospitals treat a large number of survivors [3]. In addition, hospital characteristics such as the capability for a coronary intervention (PCI) 24/7 were shown to have a significant impact on outcome after cardiac arrest [4]. Therefore, the foundation of cardiac arrest centers (CAC) in Germany, similar to the USA, is the corollary [5]. The mission of CAC is manifold. Owing to the high number of patients treated, a written standard protocol and a data registry are essential. High quality and quality management need to be transparent and reviewable at any time. Besides a structured admission process including, for example, the timing of PCI and/or CT scan, the neurological prognostication process should also follow a predefined, written timeline and standardized diagnostic steps, as this is a very sensitive and complex part of the treatment. Furthermore, CAC are preset for research and participation in international multicenter trials. Especially in cardiac arrest patients, future questions will only be answered with a high number of patients due to heterogeneity in cause of arrest and grade of hypoxia. Potential additional costs have to be part of a novel reimbursement structure concerning post-cardiac arrest therapy.

CAC are therefore necessary and needed in the near future.

\section{Financial disclosure}

CS has received honorarium and/or travel costs from Medivance, Zoll, C. R. BARD, Philips, EMCOOL, COVIDIEN and Nonin; and financial or material support for research from Medivance, Zoll, C. R. BARD, EMCOOL, COVIDIEN, Nonin and Deutsch Stiftung für Herzforschung.

\section{Declaration}

This abstract and supplement was proposed, developed and commissioned by BMC Emergency Medicine and was funded by an educational grant from C. R. BARD, NJ, USA. The published abstract was independently prepared by the author. C. R. BARD had no input into the content.

\section{Published: 24 June 2015}

\section{References}

1. Nathens AB, Jurkovich GJ, Maier RV, Grossman DC, Mackenzie EJ, Moore M, et al: Relationship between trauma center volume and outcomes. JAMA 2001, 285:1164-71.

2. Mackenzie EJ, Rivara FP, Jurkovich GJ, Nathens AB, Frey KP, Egleston BL, et al: A national evaluation of the effect of trauma-center care on mortality. N Engl J Med 2006, 354:366-78.

3. Callaway CW, Schmicker R, Kampmeyer M, Powell J, Rea TD, Daya MR, et al: Receiving hospital characteristics associated with survival after out-ofhospital cardiac arrest. Resuscitation 2010, 81:524-9.

4. Wnent J, Seewald $S$, Heringlake $M$, Lemke $H$, Brauer $K$, Lefering $R$, et al: Choice of hospital after out-of-hospital cardiac arrest - a decision with far-reaching consequences: a study in a large German city. Crit Care 2012, 16:R164

5. Kill C, FN, Scholz J, Scholz KH, Andresen D, Busch HJ, et al: Die spezialisierte Krankenhausbehandlung nach erfolgreicher Wiederbelebung ist überlebenswichtig. Notfall Rettungsmedizin 2014, 17:331-2.

\section{doi:10.1186/1471-227X-15-S1-A18}

Cite this article as: Storm: Cardiac arrest centers - the future? BMC Emergency Medicine 2015 15(Suppl 1):A18. 